\title{
VI. Simple and easy method of cleaning and whitening prints or engravings
}

\section{Fabbroni}

To cite this article: M. Fabbroni (1799) VI. Simple and easy method of cleaning and whitening prints or engravings, Philosophical Magazine Series 1, 3:11, 260-262, DOI: $10.1080 / 14786449908676992$

To link to this article: http://dx.doi.org/10.1080/14786449908676992

曲 Published online: 18 May 2009.

Submit your article to this journal $\sqsubset \pi$

Џ Article views: 2

Q View related articles $\square$ 
was totally different from thofe which have been the objects of my refearches.

The fulphurous acid gas would be ufeful in fome cafes to decompofe miafmata, by giving up to them a portion of its oxygen; but it leaves behind it an oxyd of fulphur, the fmell of which is extremely offenfive : the oxygenated muriatic acid gas ought therefore to be preferred.

The gafes which in my opinion ought to be employed for augmenting the portion of unrefpirable air, are the carbonic acid gas and hydrogen gas. The firt ought to be made to pafs through water, and the fecond through oil. By thefe means you free the carbonic acid gas from that portion of the acid employed to difengage it from the carbonat ufed, which it carries along with it; and you precipitate from the hydrogen gas the carbon it holds in folution. The oil, after being ufed fome time for this purpole, is found quite black, and converted into empyreumatic or carbonated oil.

VI. Simple and Eafy Metbod of Cleaning and Wbitening Prints or Engravings, By M. Fав в воN I. From Annali di Chimica, by Brugnatelu. Vol. XIV.

$\mathrm{T}_{1}$ HE methods formerly employed for cleaning engravings confifted in wafhing them in pure water, or a weak lixivium of pot-afh, or in expofing them a very long time to the dew. Aquafortis has alfo been fometimes employed. Leys, however, together with the dirt and filth, carried away part of the colour of the engraving, and aquafortis attacked the vegetable fibre of which the paper of the print was compofed.

Since the difcovery of the oxygenated muriatic acid by Scheele, and the application of its properties, by Berthollet, to the bleaching of cloth, trials have been made of it alfo for whitening prints and engravings; and Chaptal's experiments on this fubject were attended with the beft fuccefs $*$

* For Chaptal's procefs fee Phil. Mag. Vol. 11. p. 28. 
This procels, however, is not fo generally followed as it ought to be, chiefly becaufe the preparation of the oxygenated muriatic acid is attended with more trouble than fome people will take, and becaufe it is fometimes difficult to procure the acid ready made. This confideration induced $M$. Fabbroni to make known the following procefs, which is extremely eafy, and may be put in practice by any one.

Half fill a glafs bottle with a mixture compofed of I part of the red oxyd of lead, or minium, and 3 parts of the muriatic acid; and having clofed the mouth of the bottle with a glafs ftopper, put it in a cool place, not expofed to the light. A certain heat will then be produced, which is an indication that new combinations are formed. The oxyd of the lead abandons a confiderable portion of its oxygen, which remains combined with the liquor*; the latter then acquires a beautiful gold colour, and affumes the odour of the oxygenated muriatic acid. It holds in folution a fmall portion of the lead, which does not in the leaft injure its effect + . It is neceffary that the bottle fhould be of ftrong glafs, and that the ftopper be well fecured, in order to prevent the elaftic vapour which rifes from forcing it out. When you employ the liquor thus prepared, take a large pane of glafs, and raife a kind of border of white wax around its edge, about two inches in height, and every where equal. By thefe means you form a fort of trough, into which put the prints, and pour over them a little frefh urine; or water mixed with a portion of ox-gall. At the end of three or four

* Where the oximuriat of pot-afh can be bad, the procefs recommended by Mr. Cruick hank, of Woolwich Hofpital, will be found neater than the one here propofed. If the oxygenated muriat of potalh be fimply added to the muriatic acid, diluted with about an equal bulk of water, the falt is llowly decompofed, and the acid converted into the oxygenated acid. About I drachm of the falt, if pure, is found to be fufficient for three ounces of the dilute acid. EDrT.

+ If this be a fact, the porrion of lead held in folution muft be fmall indeed-otherwife it thould be partially revived in a length of time, and produce blacknefs, EDrt. 
days pour off whichever of thefe liquids you have employed, and fupply its place with warm water, which ought to be changed every three or four hours, until it come off perfectly clear. When the matter with which the prints are dirtied is of a refinous nature, which fometimes happens, dip them in a little alcohol: afterwards fuffer all the moifture to drain off, and cover the prints with the liquor of the oxygenated muriatic acid made by minium. Place on the edges of the wax another pane of glafs, of the fame fize as that below, in order that you may not be too much incommoded by the fmell of the acid; and you will then plainly fee the yellowert prints refume their original whitenefs. One or two hours will be fufficient to produce the defred effect. Having then poured off the acid, wath the prints, feveral times, in pure water, and dry them in the fur.

VII. Obfervations on the Britif Trade with Turkey. From Eton's Survey of the Turkith Empire.

FormerLY the trade to Turkey was of confiderable importance to this country; but of late years it had been languifhing, and at laft dwindled into a fate of infignificancy, when the prefent war entirely put a ftop to all communication with the ports of the Levant.

As this trade will be again opened when a peace takes place, an inveftigation of the caufes of its decline, and the means to give it its ancient extenfion, may not, in the mean time, be unimportant to the government and to the merchants of this country.

The caufes of its gradual decline are, Ift, The rivallhip of other European nations; adly, The diminution of the confumption of our manufactures in Turkey, by the impoverifhed ftate of the country; $3 \mathrm{dly}$, Some branches of trade being got into other channels; and 4 thly, The monopoly of the Levant Company in London. 